\title{
The Impact of Illness Awareness on the Difference in the Economic Burden of Disease Among Middle- Aged and Elderly Diabetic Patients in Rural Areas
}

\section{Li Liu}

Chongqing Medical University

Jing Deng ( $\sim$ cqmudj@126.com )

Chongqing Medical University https://orcid.org/0000-0001-6032-6529

\section{Xue Yu}

Chongqing Medical University

\section{Research}

Keywords: Diabetes, Disease awareness, Difference in economic burden of disease, PSM

Posted Date: December 3rd, 2020

DOI: https://doi.org/10.21203/rs.3.rs-117197/v1

License: (c) (i) This work is licensed under a Creative Commons Attribution 4.0 International License.

Read Full License 


\section{Abstract}

\section{Background}

There are many explorations in China on the awareness of diabetes and the economic burden of disease, but the impact of awareness of illness on the economic burden of disease has not yet been empirically studied. We aim to explore the status of illness awareness and its influencing factors in rural middle-aged and elderly diabetic patients, and to further explore the impact of illness awareness on the economic burden of patients.

\section{Methods}

Taking rural middle-aged and elderly diabetes as the object, the multiple regression model was used to analyze the patient's economic burden of disease and illness awareness, the propensity score matching method (PSM) was used to solve the influence of sample selection bias, and to explore the economic burden of disease awareness on patients Impact.

\section{Results}

Illness awareness is an important factor affecting the economic burden of disease in middle-aged and elderly diabetes in rural areas. Illness awareness increased the economic burden of disease by $94.3 \%$; the number of other chronic diseases, education level, location, self-rated health status, and smoking are Influencing factors of patients' awareness of illness.

\section{Conclusion}

In the short term, awareness of illness increases the overall treatment costs of patients, but from the perspective of long-term development, changes in lifestyle and medical behavior based on awareness of illness can help improve the health of patients and effectively reduce the risk of middle-aged and elderly diabetic patients in rural areas. The economic burden of disease.

\section{Background}

According to the International Diabetes Federation (IDF) report [1], China has the largest number of diabetes patients in the world. In 2019, there were 116.4 million diabetic patients in China. Among them, the number of undiagnosed diabetes was about 65.2 million, and the proportion of undiagnosed patients reached $56.0 \%$. It is also the country with the largest number of undiagnosed diabetes in the world. However, undiagnosed patients also have a higher risk of complications [2], which brings a heavy disease economic burden to patients and the country. There are a large number of rural residents in China, and the residents' health awareness is relatively poor. The status quo of low awareness and treatment rate of diabetes [3-5] will exacerbate this situation. Diabetes patients in rural areas often only seek medical treatment until they have serious complications, and they face a greater economic burden of disease with relatively low income levels. At present, most domestic researches only analyze the population's illness 
awareness and its influencing factors [6-8]. Few literatures quantify the impact of diabetic patients on the economic burden of their disease from the perspective of disease awareness. Insufficient attention has been paid to this special group of rural middle-aged and elderly people.

Therefore, this study analyzes the 2015 China Health and Retirement Longitudinal Study (CHARLS) data to understand the awareness and economic burden of disease among middle-aged and elderly diabetes in rural China. Misunderstanding, discuss the impact of illness awareness on the economic burden of diabetes patients, and provide a basis for the rational allocation of health resources and the formulation of effective diabetes prevention measures.

\section{Data Sources And Methods}

\section{Data source}

The data of this study comes from the 2015 CHARLS database. The survey objects are middle-aged and elderly families and individuals aged 45 and above in China. The samples cover 150 counties and 450 villages (communities) in 28 provinces (autonomous regions and municipalities) in China. There were 23,000 respondents in a total of 12,400 households, of which rural population accounted for $68.4 \%$.

\section{Target inclusion and calculation criteria}

In this study, the criteria for determining whether a patient with diabetes is one of the following criteria: (1) Fasting blood glucose level of $126 \mathrm{mg} / \mathrm{dL}$ ( $7.0 \mathrm{mmol} / \mathrm{L})$ or higher; (2) HbA1c concentration of $6.5 \%$ or higher; Or (3) Self-report that the doctor diagnosed diabetes.

Judgment of illness awareness: (1) In the CHARLS questionnaire, "Have a doctor ever told you to have the following chronic diseases?" The answer is "Yes"; or "Are the following methods currently used to treat and control diabetes?" The answer is "Yes" is conscious of illness; (2) In the CHARLS questionnaire, "Have a doctor ever told you that you have the following chronic diseases?" The answer is "No"; and "Are the following methods currently used to treat and control diabetes?" The answer is " No" means no consciousness of illness.

Patients who are judged to be diabetes and have no consciousness of illness are judged to be diabetes without consciousness of illness, a patient who is judged to be a diabetes with a illness consciousness is judged to be a patient with a illness consciousness diabetes. [9] The data screening process is shown in Figure 1.

The economic burden of disease estimated in this study is the economic burden of disease for diabetic patients. Since diabetes patients often suffer from other chronic comorbidities, it is difficult to define the part of their health expenditures that are only used to treat diabetes. Therefore, the health expenditure of diabetes with different illness awareness calculated in this study refers to all out-of-pocket health expenditures incurred by diabetes. 


\section{Method}

Diabetes' awareness of illness is not determined randomly, and is affected by a variety of factors, and there is a "selected" situation. The higher the level of education, the older the older people may have a higher rate of illness awareness, and these factors will also have an impact on the patient's economic burden of disease. Comparing the cost of the two groups of people will have certain sample selection bias. At the same time, it is impossible to clarify the net impact of illness awareness on the economic burden of the disease. Therefore, this study uses the propensity score matching model (PSM) to solve it. Based on the propensity score, the model selects individuals from the control group (awareness-free group) and matches them with the experimental group (awareness-aware group) to eliminate the heterogeneity of the two groups of samples in observable individual characteristics. It can effectively reduce the impact of sample selection bias, thereby estimating the difference effect between the experimental group and the control group [10]. The logical process of propensity score matching is as follows: First, use the linear regression model to analyze the impact of illness awareness on the economic burden of the patient's disease; second, obtain important explanatory variables that affect illness awareness according to the logit model; finally, use the PSM model to obtain propensity score value, which condenses multiple dimensions of information into one dimension, realizes the pairing of the two groups of people on the premise of meeting the common support hypothesis and the balance hypothesis, and then calculates the ATT value to test the difference between the two groups. The specific process is as follows:

\section{The impact of illness awareness on the economic burden of patients}

A multiple linear regression model was used to analyze the influencing factors of the disease economic burden of diabetes. In order to eliminate heteroscedasticity, this study used logarithmic treatment on medical expenses when doing regression analysis. Since some expenses have a value of 0 , health expenses are set to the form of $\ln$ (medical expenses +1 ). According to relevant literature research [1112], the factors included in this study are: gender, age, living status, educational attainment, basic medical insurance type, number of other chronic diseases combined, smoking, drinking, BMI, self-rated health status, location and awareness of illness. The multivariate logarithmic linear regression model is established as follows:

\section{$\ln (Y+1)=\beta_{0}+\beta_{1} X_{1}+\beta_{2} X_{2}+\cdots+\beta_{i} X_{i}+\varepsilon_{i}$}

$\mathrm{Yi}$ is the dependent variable, representing the total annual direct health expenditure, and $\ln (Y)$ represents the logarithm of the average annual direct health total expenditure. X10X2...Xi are independent variables, $\beta 1 \square \beta 2 \ldots \beta i$ are the partial regression coefficients to be estimated, $\beta 0$ is the constant term; $\varepsilon$ is the residual term. The specific variables that are assigned are shown in Table 1.

\section{Analysis of influencing factors of illness awareness}

The logit model is used to determine the influencing factors that affect the awareness of diabetes, that is, 
matching variables, the purpose of which is to complete the matching of the awareness-free group and the awareness-aware group. In this study, the awareness of illness is divided into two situations: "awareness of illness" and "awareness of no illness". Therefore, a binary logit model is used to analyze the influencing factors of the illness awareness of diabetes, and the influencing factor variables are included as above. The two-class logit regression model is established as follows:

$$
\operatorname{logit}(Y)=\beta_{0}+\beta_{1} X_{1}+\beta_{2} X_{2}+\cdots+\beta_{i} X_{i}+\varepsilon_{i}
$$

$Y$ is a binary variable, $Y=0$ means no awareness of illness, $Y=1$ means have awareness of illness, $X 10 X 2 \ldots$ $\mathrm{Xi}$ are factors that affect awareness of illness, and the variables included are the same as above.

\section{Analysis of the effect of illness awareness processing (PSM)}

First, assuming that whether an individual has illness awareness is determined by various observable factors, use the logit model to estimate the probability of disease awareness, that is, the propensity score (PS):

$p_{i}(x)=\operatorname{pr}\left(\right.$ awareness $\left.=1 \mid X_{i}\right)=F\left[h\left(x_{i}\right)\right]$

Among them, awareness is the dependent variable, which represents whether the diabetes has illness awareness (awareness $=1$, yes; awareness $=0$, no), $X i$ represents a series of characteristic variables that an individual has disease awareness, and the variables included are the same as above.

Second, the sample matching effect test. It mainly depends on whether there are systematic differences in the sample characteristics between the experimental group and the control group after matching. There are mainly common support hypothesis testing and balanced hypothesis testing. The former aims to ensure that the experimental group can be well matched, and the latter aims to ensure that there is no difference between the two groups after matching. In order to isolate the net effect of illness awareness on the economic burden of diabetic patients.

Finally, calculate the average treatment effect. By comparing the difference in the total direct health expenditure between the experimental group and the control group, the impact of illness awareness on the economic burden of the patient's disease is obtained, which is the ATT estimate. In order to ensure the robustness of the estimation results, this study selects nearest neighbor matching (1 to 1 without replacement), radius matching (caliper value 0.01 ) and kernel matching for sample matching. If the matching estimation results of the three methods are similar, the estimation is indicated The result is stable and reliable. The expression of ATT estimator is:

$$
A T T=\frac{1}{N_{1}} \Sigma_{i: D_{l}=1}\left(y_{i}-y_{0 i}\right)
$$

In the above formula, $\mathrm{N} 1=\sum 1 \mathrm{Di}$ refers to the number of samples in the experimental group, $\sum \mathrm{i}: D i$ refers to only adding up the samples in the experimental group, yi is the disease economic burden of the 
samples in the experimental group, and $y 0 \mathrm{i}$ is the control after matching The economic burden of disease of the group sample.

\section{Results}

\section{Awareness of illness among middle-aged and elderly patients with diabetes in rural}

According to the CHARLS database, there were 2173 rural middle-aged and elderly diabetic patients in China in 2015. The actual prevalence rate of diabetes (including those with and without disease awareness) was $15.94 \%$. The prevalence of diabetes with (without) awareness of illness is the ratio of the number of patients with (without) awareness of the illness to the total number of people in the survey. In this study, there were 1041 unconscious patients, and the prevalence of unconscious diabetes was 7.64\%; 1132 patients were conscious, and the prevalence of conscious diabetes was $8.31 \%$. Among all diabetes in rural areas, the proportion of patients without illness awareness reached $47.91 \%$.

\section{The impact of illness awareness on the economic burden of patients}

From the analysis results, column (1) of Table 2 examines the analysis results that only include the explanatory variable of illness awareness. The coefficient of influence of illness awareness on the economic burden of patients' disease is 1.65 , which is significant at the $1 \%$ level; Column (2) includes factors that affect the economic burden of the patient's disease in addition to the awareness of illness according to other related studies. The coefficient of influence of the awareness of illness is 1.00 , which is still significant at the level of $1 \%$. It can be seen that the awareness of illness is an important explanatory variable for the economic burden of diabetes, and it has a positive effect. But it cannot solve the impact of sample selection bias. Column (3) is the logit analysis result with disease awareness as the explained variable. The results show that whether a diabetes has illness awareness is positively correlated with the number of other chronic diseases, location, and education attainment, and is related to smoking and self-evaluation health status is negatively correlated. In the following analysis, the explanatory variables in column (3) are used as matching variables.

\section{The average treatment effect of illness awareness on the economic burden of disease}

\section{Analysis of matching effect}

The common support hypothesis requires that the sample feature distributions of the control group and the experimental group overlap to a certain extent to ensure the matching quality. As shown in Table 3 , most of the samples in the control group and the experimental group meet the common support hypothesis. Excluding a small number of samples, it has little effect on the average treatment effect estimation result and meets the common support condition.

The test results of the matching balance of each variable show that there is no difference between the individual characteristic variables of the experimental group and the control group after matching, and the absolute value of the standard deviation is less than $10 \%$, which is less than the absolute value of the 
standard deviation defined by Rosenbaum and Rubin less than $20 \%$ Standard [10]. This shows that the matching effect is better, and the parallel hypothesis is satisfied (see Table 4). The inspection results of the radius matching method and the kernel matching method are similar to those in Table 4, and will not be repeated here.

\section{Analysis of matching results}

It can be seen from Table 5 that the results of the three matching methods all show that the economic burden of disease in the experimental group and the control group is significant at the level of $1 \%$. It can be seen that after controlling other variables that affect the economic burden of disease, illness awareness can still have a significant impact on the economic burden of diabetes, indicating that illness awareness is an important factor affecting the economic burden of patients. On the premise that other conditions that affect the economic burden of the disease are the same, having illness awareness increases the economic burden of the disease of diabetes by an average of $94.3 \%$. The main reason is that when diabetes know that they are sick, they will subjectively use health services more frequently, which will increase their medical expenses in the short term.

\section{Discussion}

Sickness awareness promotes the economic burden of disease for patients, and the potential economic burden of disease is large for patients without awareness. From the data analysis results in this paper, the awareness of illness makes the total annual direct health expenditure of middle-aged and elderly diabetic patients in China's rural areas $94.3 \%$ higher than that of patients without awareness of illness, indicating that illness awareness is an important factor affecting the economic burden of patients. Awareness of illness is the first step in generating health service utilization and related costs. However, studies have found that the proportion of related health care and drug use increases before the first diagnosis of diabetes [13], and related health costs incurred by patients with diabetes start at least before the diagnosis 8 years, and with the approach of diagnosis and the rapid growth in recent years after diagnosis [14], this indicates that there are diabetes-related health service utilization and expenses in Non-diseased diabetes. A study in the United States showed that the per capita medical expenses of nondiabetic patients with diabetes need to spend an extra US\$2864/year [15]. The health expenses of patients with diabetes without awareness of illness are lower than those with awareness of illness, which may be related to the lower utilization rate of their health services. In this study, the utilization rate of health services for patients with illness awareness was $78.36 \%$, which was significantly higher than that of unconsciousness (64.07\%). At the same time, patients without awareness of illness have less or no use of health services, which increases the possibility that their illness will not be detected. In the long run, with the change of awareness of illness and the delay of medical treatment, serious complications and physical damage may be caused, which will bring a heavier disease economic burden.

Multiple factors affect the change of illness consciousness. The number of other chronic diseases combined is an important factor that affects the awareness of illness. The change from patients without 
awareness of illness to patients with awareness of illness is accompanied by an increase in the number of chronic complications. The early symptoms of diabetes are often not obvious, and patients often find that they have diabetes after the emergence of complications of diabetes. Middle-aged and elderly patients in rural areas have relatively weak self-care awareness, coupled with poor access to medical resources in rural areas, the chance of discovering diabetes and its chronic comorbidities is relatively small, which directly affects the transformation of disease awareness. In the state of non-diseased consciousness, patients generally do not take the initiative to take treatment and control measures. As the disease becomes more serious, the risk and number of other complications will increase. Diabetes is further diagnosed through other chronic comorbidities, and it is more likely to change from being diseasefree to being disease-conscious.

The level of education has a positive effect on the awareness of diabetes. The higher the level of education, the higher the awareness rate. Compared with low-level patients, patients with high levels of education are more willing to accept health care knowledge, have more channels, and can make full use of the medical and health resources available around them. Therefore, to a certain extent, their awareness of illness has changed. It is more likely to detect diseases early.

There are regional differences in the awareness rate of diabetes. The awareness rate of diabetes patients in rural areas in the east is higher than that in the west, which to a certain extent indicates that socioeconomic and health service inequality is an important risk factor affecting patients' awareness [16]. There are significant regional differences in the level of economic development in China. The eastern region is economically developed. Compared with the underdeveloped regions in the western region, the corresponding eastern rural areas also have higher economic development capabilities and health service levels, and medical resources are more accessible. People with diabetes are more likely to find that they have diabetes.

The self-evaluated health status of patients with illness awareness was worse than that of patients without illness awareness. Chronic diseases have a greater impact on self-rated health status, and selfrated health subjectively reflects personal health information, which in turn can make good predictions about related diseases [17]. Diabetes patients with poor self-rated health usually have more severe health conditions and even more serious complications, which makes the patient's subjective feelings more obvious, thus speeding up the use of health services to promote disease diagnosis. Diabetes is a chronic disease, and its early symptoms are not obvious. Therefore, patients' evaluation of their own health status will not be greatly affected, and their demand for health services is not high, which delays the transition of illness awareness.

Smoking has a negative effect on patients' awareness of disease. The awareness rate of diabetes patients who smoke is lower than that of non-smokers, which is consistent with the results of other studies [5]. This means that patients without awareness of illness are more likely to adopt unhealthy lifestyles. Smoking increases the risk of diabetes-related complications and premature death[18], and this part of the population does not pay enough attention to the degree of smoking hazards and their own 
health conditions. They may not seek medical treatment in time even if they have early symptoms of diabetes, which reduces the possibility of disease being discovered. At the same time, it also brings greater health risks to patients without awareness of illness, and the condition further develops without good control, which increases the potential demand for medical services in the later period.

The actual prevalence of diabetes in rural middle-aged and elderly people is high, and the proportion of patients without awareness of the illness is relatively large. According to the CHARLS database, the actual prevalence of diabetes in rural areas in China is $15.94 \%$, which is significantly higher than the $7.2 \%$ found in the Fifth National Health Service Survey in 2013. This may be related to the increase in the number of diabetes in rural areas by the inclusion of patients without illness awareness. Among diabetes, $47.91 \%$ of patients are not aware of the disease, which is higher than $31.1 \%$ in Jilin Province [19] and $35.4 \%$ in Qinghai Province [20]. This may be related to the data in this study from the CHARLS database. The quantity is large, the coverage area is wide, and the rural residents are selected in this study. Due to the limited resources and the lack of extensive screening programs, it may lead to a larger proportion of patients with no awareness of illness in rural areas. At the same time, it also reflects the problem of weak awareness of diabetes in rural areas in China to a certain extent.

Based on the above research, this article puts forward the following suggestions: First, strengthen the early diagnosis of disease-free diabetes, improve the awareness of diabetes in rural middle-aged and elderly diabetes, so as to improve the utilization of health services, delay the development of disease and the occurrence of complications, and effectively reduce the economic burden of patients' disease in the long run .Second, take targeted measures to promote the transformation of patients' awareness of illness, implement diabetes management strategies centered on the screening of diabetes combined with chronic complications, and focus on the rural primary medical service network and economically underdeveloped areas to spread health knowledge, diabetes follow-up monitoring strategies based on healthy lifestyle interventions, to improve the detection of disease-free patients and the progress of disease awareness. At the same time, it can also enable patients to reduce the impact of disease risk factors without awareness of illness, and improve the health status of patients without awareness of illness.

\section{Conclusion}

In general, the awareness of illness is an important factor affecting the economic burden of patients with diabetes, which increases the overall treatment costs of patients in the short term. However, from the perspective of long-term development, based on the change in awareness of illness, it will bring about changes in medical treatment, living habits and lifestyle, change and delay the direction and progress of disease development, and help improve the health of patients. It can effectively reduce the economic burden of disease for middle-aged and elderly diabetic patients in rural areas.

\section{Abbreviations}

CHARLS (2015):China Health and Retirement Longitudinal Study(2015) 


\section{Declarations}

\section{Ethics approval and consent to participate}

Not applicable

\section{Consent for publication}

Not applicable

\section{Availability of data and materials}

The dataset(s) supporting the conclusions of this article is(are) available in the [China Health and Retirement Longitudinal Study] repository, http://charls.pku.edu.cn/

\section{Competing interests}

The authors declare that they have no competing interests

\section{Funding}

This project was supported by Chongqing Social Science Planning Project: Research on Risk Assessment and Management Strategy of Poverty Caused by Diseases of the Poor Population in Chongqing (2020YBGL97)

\section{Authors' contributions}

Li LIU is responsible for writing the article; Xue YU are responsible for data extraction and analysis; Jing DENG has made precise revisions to the full text. All authors read and approved the final manuscript.

\section{References}

[1] Cho.IDF diabetes atlas - 9th edition.International Diabetes Federation, Nam H.2019. https://diabetesatlas.org/en/. Accessed 28 May 2020.

[2] Y Zhang, Dall TM $\mathbb{M}$ Mann SE, et al. The economic costs of undiagnosed diabetes. Population Health Management $₫ 2009 ; 12(2): 95-101$.

[3] Gu JF. Interpretation of "Report on Nutrition and Chronic Disease Status of Chinese Residents (2015)". Journal of Nutrition,2016;38(06):525-529.

[4]Zhao WH. Research on the Direct Economic Burden of Diabetes. Peking Union Medical College,2012.

[5] Wang C, Li Y, He Huan, et al. Analysis of the status quo and influencing factors of diabetes awareness, treatment and control rates of rural residents in Jilin Province. Health Research,2014;43(05):784-789. 
[6] Li JB, Liu JX, Wang YH, et al. Analysis on the status quo of awareness, treatment and control of diabetes among adult residents in Zhengzhou .China Health Education,2020;36(09):797-800.

[7] Xie QM, Huang YX, Chen FM, et al. Analysis of the Awareness Rate of Adult Diabetes in Changsha City and Its Influencing Factors .Chinese Disease Control Research,2016;20(11):1088-1091.

[8] Bai Y, Geng K, Xu ZX, et al. Epidemiological status and influencing factors of adult diabetes in Changping District, Beijing in 2017 . Occupation and Health,2020;36(02):175-179.

[9] Li C,Lumey L H,Impact of disease screening on awareness and management of hypertension and diabetes between 2011 and 2015:results from the China health and retirement longitudinal study. BMC Public Health, 2019;19(1).

[10] Rosenbaum,P.R.खRubin,D.B.(1983).The Central Role of the Propensity Score in Observational Studies for Causal Effects $₫$ Biometrika,70(1):41囚55.

[11] Ye ZS. Study on the status quo of the economic burden of diabetes in Zhuhai and its influencing factors .Jinan University,2017.

[12] Ming XY, Yang L, Sun Q, et al. Analysis of Economic Burden and Influencing Factors of Diabetes in Sichuan Province .Health Economics Research,2019;36(01):29-31+37.

[13] Gulliford MC, Charlton Judith, Latinovic R. Increased utilization of primary care 5 years before diagnosis of type 2 diabetes: a matched cohort study. Diabetes care,2005;28(1):47-52.

[14] Nichols GA, Glauber HS, Brown JB. Type 2 diabetes: incremental medical care costs during the 8 years preceding diagnosis. Diabetes Care 2000;23(11):1654-1659.

[15] Zhang Y, Dall TM, Mann SE, et al. The economic costs of undiagnosed diabetes. Popul Health Manag, 2009,;12(2): 95-101.

[16] Millar S. R,Connor J. M. O ,Buckley C. M, et al. The Prevalence and Determinants of Undiagnosed and Diagnosed Type 2 Diabetes in Middle-Aged Irish Adults. International Journal of Epidemiology,2015,;suppl1 44.

[17] Fu ZX, Jin DH, Chen BY, et al. The prevalence of major chronic diseases of adults in Liuyang and their influence on self-evaluation of health .Practical Preventive Medicine,2018,25(12):1416-1421.doi:

CNKI:SUN:SYYY.0.2018-12-003

[18] Chinese Diabetes Society. Guidelines for the Prevention and Treatment of Type 2 Diabetes in China (2017 Edition) .Chinese Journal of Practical Internal Medicine,2018;38(04):292-344.

[19] Wang C. Analysis of the status quo and influencing factors of the awareness, treatment and control rates of adult diabetes in Jilin Province .Jilin University,2015. 
[20] Ma FC, Zhou MR, Yue JN, et al. The prevalence, awareness, treatment and control of major chronic diseases among adult residents in parts of Qinghai Province .Chronic Disease Prevention and Control in China.2015;23(11) : 854-856.

\section{Tables}

\section{Table 1 Variables and assignments}

\begin{tabular}{|c|c|c|c|}
\hline \multirow[t]{2}{*}{ Variable } & \multirow[t]{2}{*}{ Assignment } & \multicolumn{2}{|c|}{ Total sample } \\
\hline & & Mean & $\begin{array}{l}\text { Standard } \\
\text { Deviation }\end{array}$ \\
\hline \multicolumn{4}{|l|}{$\begin{array}{l}\text { Explained } \\
\text { Variable }\end{array}$} \\
\hline $\begin{array}{l}\text { Total annual } \\
\text { direct health } \\
\text { expenditure }\end{array}$ & Logarithmic Form & 4.83 & 3.44 \\
\hline \multicolumn{4}{|l|}{$\begin{array}{l}\text { Explanatory } \\
\text { variables }\end{array}$} \\
\hline Gender & $1=$ Male $\varangle 2=$ Female & 1.57 & 0.50 \\
\hline Age & Actual Value & 62.26 & 9.37 \\
\hline $\begin{array}{l}\text { Living } \\
\text { Condition }\end{array}$ & $\begin{array}{l}1=\text { Others (unmarried, divorced, widowed, etc.); } 2=\text { Married and } \\
\text { Live Together }\end{array}$ & 1.80 & 0.40 \\
\hline $\begin{array}{l}\text { Educational } \\
\text { attainment }^{\text {a }}\end{array}$ & $\begin{array}{l}1=\text { Illiteracy; } 2=\text { Elementary Education; } 3=\text { Secondary } \\
\text { Education; } 4=\text { Higher Education }\end{array}$ & 1.22 & 0.42 \\
\hline $\begin{array}{l}\text { Types of } \\
\text { Medical } \\
\text { Insurance }\end{array}$ & $\begin{array}{l}\text { 1=No Insurance;2=Urban Employee Medical } \\
\text { Insurance; } 3=\text { Urban Resident Medical Insurance;4=New Rural } \\
\text { Cooperative Medical Insurance }\end{array}$ & 3.41 & 1.12 \\
\hline $\begin{array}{l}\text { Number of } \\
\text { Other Chronic } \\
\text { diseases }\end{array}$ & Actual Value & 2.43 & 1.84 \\
\hline Smoking & $0=\mathrm{N} 0 \otimes 1=\mathrm{Yes}$ & 0.24 & 0.43 \\
\hline Drinking & $0=\mathrm{N} 0 \otimes 1=\mathrm{Yes}$ & 0.43 & 0.50 \\
\hline $\mathrm{BMI}^{\mathrm{b}}$ & $1=$ Low weight $₫ 2=$ Normal $₫ 3=$ Overweight; $4=$ Obesity & 2.42 & 1.17 \\
\hline $\begin{array}{l}\text { Self-rated } \\
\text { Health }\end{array}$ & $0=$ Poor $\otimes 1=$ General $\triangle 2=$ Good & 0.87 & 0.66 \\
\hline Location & $1=$ West $; 2=$ Central;3=East & 2.06 & 0.82 \\
\hline
\end{tabular}


Note: a. In the variable of Educational attainment, 1 means illiteracy and has not graduated from elementary school, 2 means graduated from elementary school or junior high school, 3 means graduated from high school or technical secondary school, 4 means graduated from college or above;

b. BMI classification standard: According to the "Guidelines for the Prevention and Control of Overweight and Obesity in Adults in China": BMl $<18.5 \mathrm{~kg} / \mathrm{m} 2$ means low weight, $18.5 \mathrm{~kg} / \mathrm{m} 2 \leq B M l<24 \mathrm{~kg} / \mathrm{m} 2$ means normal weight, $24 \mathrm{~kg} / \mathrm{m} 2 \leq \mathrm{BMl}<28 \mathrm{~kg} / \mathrm{m} 2$ means overweight, and $\mathrm{BMl} \geq 28 \mathrm{~kg} / \mathrm{m} 2$ means obesity.

\section{Table 2 Analysis of influencing factors of illness awareness}

\begin{tabular}{|llll|}
\hline variable & $(1)$ & $(2)$ & $(3)$ \\
\hline Illness Awareness & $1.653^{\star \star \star}$ & $1.005^{\star \star \star}$ & $\backslash$ \\
\hline Gender & $\backslash$ & -0.140 & 0.131 \\
\hline Age & $\backslash$ & -0.001 & -0.004 \\
\hline Living Condition & $\backslash$ & 0.101 & 0.177 \\
\hline Educational attainment & $\backslash$ & $0.373^{\star \star}$ & $0.323^{\star \star \star}$ \\
\hline Types of Medical Insurance & $\backslash$ & -0.057 & -0.058 \\
\hline Number of Other Chronic diseases & $\backslash$ & $0.378^{\star \star \star}$ & $0.261^{\star \star \star}$ \\
\hline Smoking & $\backslash$ & $-0.502^{\star \star *}$ & $-0.282^{\star \star}$ \\
\hline Drinking & $\backslash$ & 0.238 & -0.102 \\
\hline BMI & $\backslash$ & $0.171^{\star \star \star}$ & -0.038 \\
\hline self-evaluation health status & $\backslash$ & $-0.878^{\star \star \star}$ & $-0.485^{\star \star \star}$ \\
\hline Area & $\backslash$ & $-0.262^{\star \star \star}$ & $0.168^{\star \star \star}$ \\
\hline Constant & $3.965^{\star \star \star}$ & $4.122^{\star \star \star}$ & -0.703 \\
\hline
\end{tabular}

Notes $\rrbracket^{*}$ Significant at $10 \%$ confidence level

**Significant at $5 \%$ confidence level

$\star \star \star$ Significant at $1 \%$ confidence level

Table 3 Common support hypothesis analysis 


\begin{tabular}{|c|c|c|c|c|c|c|}
\hline \multirow[t]{3}{*}{ Group } & \multicolumn{2}{|c|}{$\begin{array}{l}\text { Nearest Neighbor } \\
\text { Matching }\end{array}$} & \multicolumn{2}{|c|}{ Radius Matching } & \multicolumn{2}{|c|}{ Kernel Matching } \\
\hline & $\begin{array}{l}\text { Non- } \\
\text { common }\end{array}$ & $\begin{array}{l}\text { Common } \\
\text { value }\end{array}$ & $\begin{array}{l}\text { Non- } \\
\text { common }\end{array}$ & $\begin{array}{l}\text { Common } \\
\text { value }\end{array}$ & $\begin{array}{l}\text { Non- } \\
\text { common }\end{array}$ & $\begin{array}{l}\text { Common } \\
\text { value }\end{array}$ \\
\hline & value & & value & & value & \\
\hline $\begin{array}{l}\text { Control } \\
\text { Group }\end{array}$ & 7 & 1034 & 7 & 1034 & 2 & 1039 \\
\hline Test Group & 24 & 1108 & 24 & 1108 & 15 & 1117 \\
\hline Total & 31 & 2142 & 31 & 2142 & 17 & 2156 \\
\hline
\end{tabular}

Table 4 Changes of characteristic variables before and after sample matching 


\begin{tabular}{|c|c|c|c|c|c|c|c|}
\hline \multirow[t]{2}{*}{ Variable } & \multirow[t]{2}{*}{ Sample } & \multicolumn{2}{|l|}{ Mean } & \multirow[t]{2}{*}{$\mathrm{SD} /(\%)$} & \multirow{2}{*}{$\begin{array}{l}\text { SD } \\
\text { reduction/(\%) }\end{array}$} & \multicolumn{2}{|l|}{ t-test } \\
\hline & & $\begin{array}{l}\text { Test } \\
\text { Group }\end{array}$ & $\begin{array}{l}\text { Control } \\
\text { Group }\end{array}$ & & & $\begin{array}{l}t \\
\text { value }\end{array}$ & $\begin{array}{l}P \\
\text { value }\end{array}$ \\
\hline \multirow[t]{2}{*}{ Gender } & $\begin{array}{l}\text { Before } \\
\text { matching }\end{array}$ & 1.60 & 1.53 & 15 & \multirow[t]{2}{*}{69.6} & 3.5 & 0.000 \\
\hline & $\begin{array}{l}\text { After } \\
\text { matching }\end{array}$ & 1.60 & 1.62 & -4.6 & & -1.09 & 0.277 \\
\hline \multirow[t]{2}{*}{ Age } & $\begin{array}{l}\text { Before } \\
\text { matching }\end{array}$ & 62.35 & 62.17 & 1.8 & \multirow[t]{2}{*}{9.9} & 0.43 & 0.667 \\
\hline & $\begin{array}{l}\text { After } \\
\text { matching }\end{array}$ & 62.38 & 62.53 & -1.7 & & -0.4 & 0.690 \\
\hline \multirow[t]{2}{*}{ Living Condition } & $\begin{array}{l}\text { Before } \\
\text { matching }\end{array}$ & 1.81 & 1.79 & 6 & \multirow[t]{2}{*}{24.7} & 1.4 & 0.161 \\
\hline & $\begin{array}{l}\text { After } \\
\text { matching }\end{array}$ & 1.81 & 1.80 & 4.5 & & 1.07 & 0.284 \\
\hline \multirow[t]{2}{*}{$\begin{array}{l}\text { Educational } \\
\text { Attainment }\end{array}$} & $\begin{array}{l}\text { Before } \\
\text { matching }\end{array}$ & 1.24 & 1.20 & 7.4 & \multirow[t]{2}{*}{88.5} & 1.73 & 0.084 \\
\hline & $\begin{array}{l}\text { After } \\
\text { matching }\end{array}$ & 1.23 & 1.23 & -0.9 & & -0.2 & 0.843 \\
\hline \multirow[t]{2}{*}{$\begin{array}{l}\text { Types of Medical } \\
\text { Insurance }\end{array}$} & $\begin{array}{l}\text { Before } \\
\text { matching }\end{array}$ & 3.39 & 3.44 & -5.3 & \multirow[t]{2}{*}{87.9} & -1.24 & 0.214 \\
\hline & $\begin{array}{l}\text { After } \\
\text { matching }\end{array}$ & 3.39 & 3.40 & -0.6 & & -0.15 & 0.880 \\
\hline \multirow[t]{2}{*}{$\begin{array}{l}\text { Number of Other } \\
\text { Chronic diseases }\end{array}$} & $\begin{array}{l}\text { Before } \\
\text { matching }\end{array}$ & 2.87 & 1.94 & 52.7 & \multirow[t]{2}{*}{95.2} & 12.23 & 0.000 \\
\hline & $\begin{array}{l}\text { After } \\
\text { matching }\end{array}$ & 2.77 & 2.73 & 2.5 & & 0.59 & 0.557 \\
\hline \multirow[t]{2}{*}{ Smoking } & $\begin{array}{l}\text { Before } \\
\text { matching }\end{array}$ & 0.20 & 0.28 & -19 & \multirow[t]{2}{*}{73.3} & -4.43 & 0.000 \\
\hline & $\begin{array}{l}\text { After } \\
\text { matching }\end{array}$ & 0.21 & 0.18 & 5.1 & & 1.29 & 0.198 \\
\hline \multirow[t]{2}{*}{ Drinking } & $\begin{array}{l}\text { Before } \\
\text { matching }\end{array}$ & 0.41 & 0.46 & -10.5 & \multirow[t]{2}{*}{87.9} & -2.45 & 0.015 \\
\hline & $\begin{array}{l}\text { After } \\
\text { matching }\end{array}$ & 0.41 & 0.41 & 1.3 & & 0.3 & 0.762 \\
\hline \multirow[t]{2}{*}{ BMI } & $\begin{array}{l}\text { Before } \\
\text { matching }\end{array}$ & 2.45 & 2.38 & 6.1 & \multirow[t]{2}{*}{12.3} & 1.42 & 0.157 \\
\hline & $\begin{array}{l}\text { After } \\
\text { matching }\end{array}$ & 2.45 & 2.39 & 5.3 & & 1.25 & 0.210 \\
\hline
\end{tabular}




\begin{tabular}{|lllllllll|}
\hline Self-rated Health & $\begin{array}{l}\text { Before } \\
\text { matching }\end{array}$ & 0.72 & 1.02 & -46.2 & 99.4 & & -10.76 & 0.000 \\
& $\begin{array}{l}\text { After } \\
\text { matching }\end{array}$ & 0.74 & 0.74 & 0.3 & & & 0.07 & 0.946 \\
\hline Location & $\begin{array}{l}\text { Before } \\
\text { matching }\end{array}$ & 2.09 & 2.04 & 6.8 & 77.2 & & 1.58 & 0.115 \\
\hline & $\begin{array}{l}\text { After } \\
\text { matching }\end{array}$ & 2.09 & 2.10 & -1.5 & & & -0.36 & 0.718 \\
\hline
\end{tabular}

\section{Table 5 ATT estimated values analyzed by PSM}

\begin{tabular}{|lllllll|}
\hline Matching Method & & $\begin{array}{l}\text { Test } \\
\text { Group }\end{array}$ & $\begin{array}{l}\text { Control } \\
\text { Group }\end{array}$ & ATT & SE & $\begin{array}{c}t \\
\text { value }\end{array}$ \\
\hline $\begin{array}{l}\text { Nearest Neighbor } \\
\text { Matching }\end{array}$ & $\begin{array}{l}\text { Before } \\
\text { Matching }\end{array}$ & 5.62 & 3.97 & 1.65 & 0.14 & 11.52 \\
\hline & After Matching & 5.58 & 4.64 & 0.94 & 0.20 & $4.61^{\star \star \star}$ \\
\hline Radius Matching & $\begin{array}{l}\text { Before } \\
\text { Matching }\end{array}$ & 5.62 & 3.97 & 1.65 & 0.14 & 11.52 \\
\hline Kernel Matching & $\begin{array}{l}\text { After Matching } \\
\text { Before }\end{array}$ & 5.58 & 4.68 & 0.90 & 0.17 & $5.44^{\star \star \star}$ \\
\hline $\begin{array}{l}\text { Matching } \\
\text { After Matching }\end{array}$ & 5.62 & 3.97 & 1.65 & 0.14 & 11.52 \\
\hline
\end{tabular}

Notes $\nabla^{*}$ Significant at $10 \%$ confidence level

**Significant at $5 \%$ confidence level

$\star \star \star$ Significant at $1 \%$ confidence level

\section{Figures}




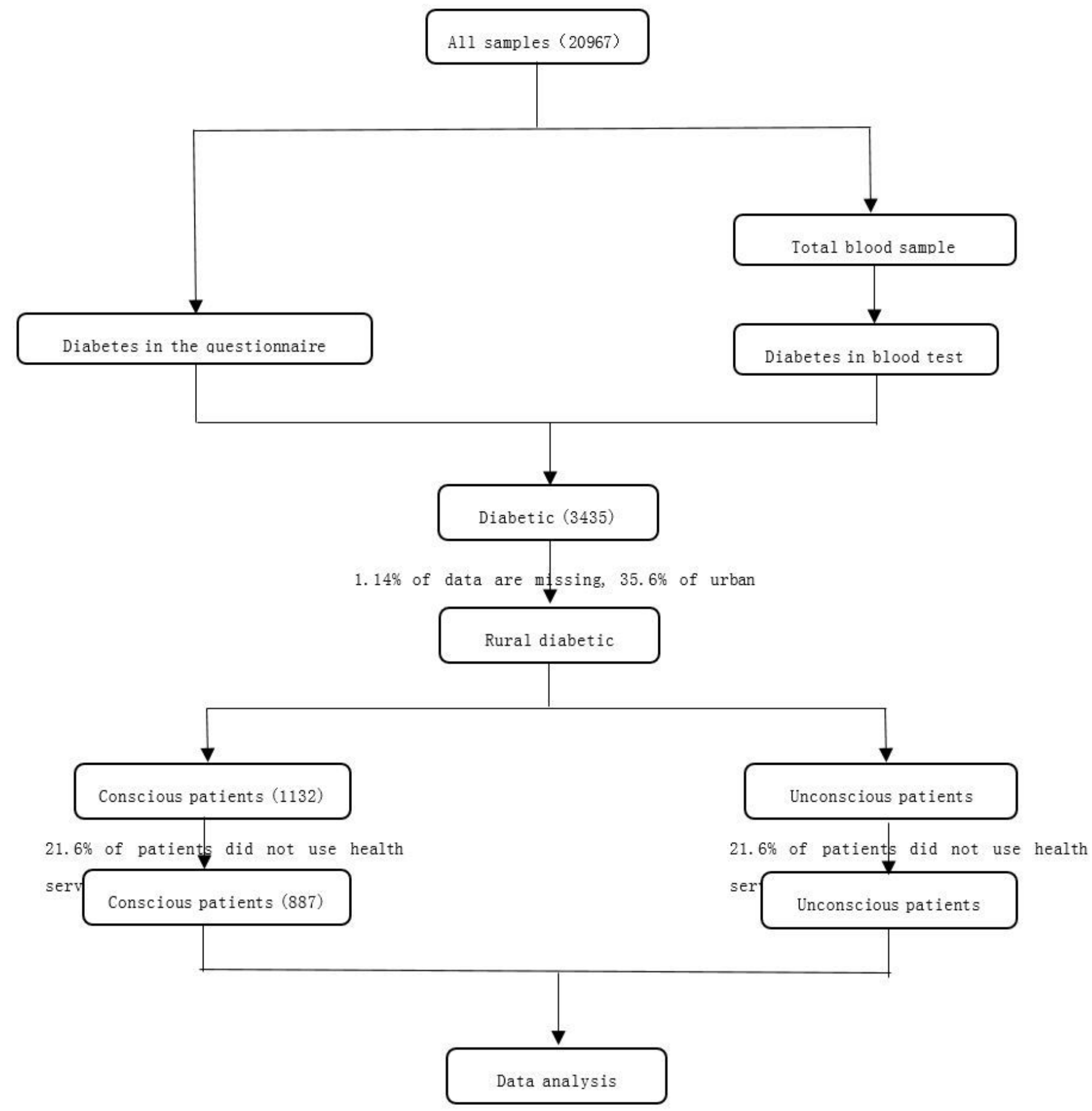

Figure 1

Data screening process 


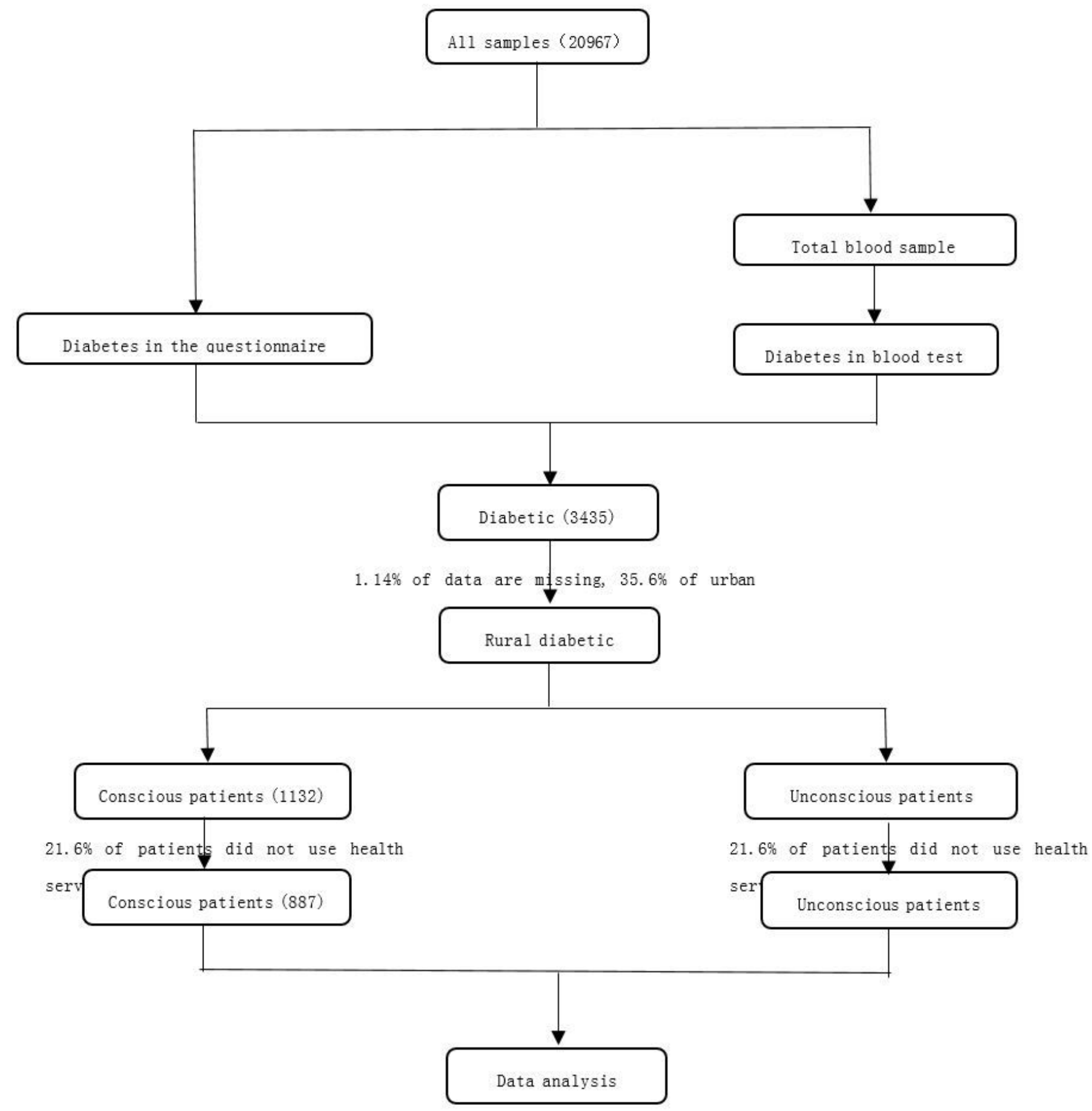

Figure 1

Data screening process 